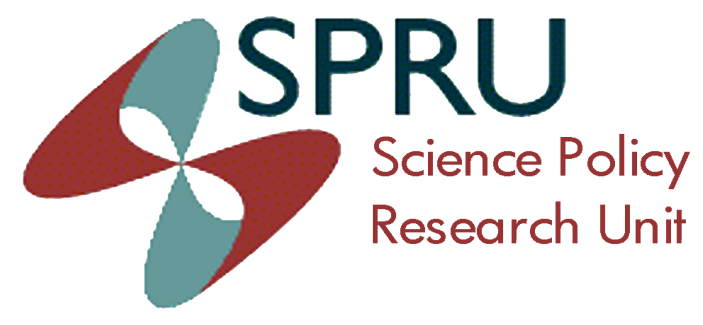

Working Paper Series

SWPS 2014-17

September, 2014

How satisfied are the self-employed? A life domain view

Martin Binder

Alex Coad 


\section{SPRU Working Paper Series}

The SPRU Working Paper Series aims to accelerate the public availability of the research undertaken by SPRUassociated people of all categories, and exceptionally, other research that is of considerable interest within SPRU. It presents research results that in whole or part are suitable for submission to a refereed journal, to a sponsor, to a major conference or to the editor of a book. Our intention is to provide access to early copies of SPRU research.

\section{Editors}

Tommaso Ciarli

Daniele Rotolo

\section{Associate Editors}

Florian Kern

Paul Nightingale

Matias Ramirez

Joe Tidd \&

Carlos Sato

Maria Savona \&

Mariana Mazzucato

Andrew Stirling

Caitriona McLeish

\section{Area}

Energy

Science, \& Technology Policy

Development

Technology Innovation Management

Economics of Technological Change

Transitions

Civil military interface

\section{Contact}

T.Ciarli@sussex.ac.uk

D.Rotolo@sussex.ac.uk
F.Kern@sussex.ac.uk

P.Nightingale@sussex.ac.uk

Matias.Ramirez@sussex.ac.uk

J.Tidd@sussex.ac.uk

C.E.Y.Sato@sussex.ac.uk

M.Savona@sussex.ac.uk

M.Mazzucato@sussex.ac.uk

A.C.Stirling@sussex.ac.uk

C.A.McLeish@sussex.ac.uk

\section{Disclaimer}

The works available here are the responsibility of the individual author(s) and do not necessarily represent the views of other SPRU researchers. As matters of policy and practice, SPRU does not endorse individual research contributions.

\section{Guidelines for authors}

Papers shall be submitted in pdf or Word format. They should contain a title, an abstract, and keywords. Papers should be submitted to one of the Editors, who will process them and send them to the appropriate Associate Editor. Two members of SPRU will be asked to provide a short written review within three weeks. The revised versions of the paper, together with a reply to the reviewers, should be sent to the Associate Editor, who will propose to the Editors its publication on the series. When submitting the authors should indicate if the paper has already undergone peer-reviewing, in which case the Associate Editors may decide to skip internal review process.

\section{Website}

SWPS: www.sussex.ac.uk/spru/research/swps

IDEAS: ideas.repec.org/s/sru/ssewps.html 


\title{
How satisfied are the self-employed? A life domain view ${ }^{\text {th }}$
}

\author{
Martin Binder,a,b,c, Alex Coad ${ }^{\mathrm{c}, \mathrm{d}, \mathrm{e}}$ \\ ${ }^{a}$ Bard College Berlin, Platanenstr. 24, 13156 Berlin, Germany \\ ${ }^{b}$ Max Planck Institute of Economics, Evolutionary Economics Group, Kahlaische Str.10, 07745 Jena, \\ Germany \\ ${ }^{c}$ Science and Technology Policy Research Unit, University of Sussex, Falmer, Brighton, BN1 9SL, UK \\ ${ }^{d}$ RATIO, P.O. Box 3203, SE-10364 Stockholm, Sweden \\ ${ }^{e}$ Department of Business and Management, Aalborg University, Fibigerstrade 4, 9220 Aalborg Ø, DK
}

\begin{abstract}
It is well-known in the literature that self-employment positively influences job satisfaction, but the effects on other life domains and overall life satisfaction are much less clear. Our study analyzes the welfare effects of self-employment apart from its monetary aspects, and focuses on the overall life satisfaction as well as different domain satisfactions of self-employed individuals in our German sample from 1997 to 2010. Using matching estimators to create an appropriate control group and differentiating between different types of self-employment, we find that voluntary self-employment brings with it positive benefits apart from work satisfaction, and leads to higher overall life satisfaction as well as increased health satisfaction, all of which increase in the first three years of self-employment. Being forced into selfemployment to escape unemployment, however, confers no such benefits. Additionally, both types of self-employment lead to increasing dissatisfaction with one's leisure time.
\end{abstract}

Key words: subjective well-being, self-employment, domain satisfaction, matching estimators, SOEP JEL-classification: L26, J24, J28

\footnotetext{
${ }^{\star 2}$ We are grateful to Simon Parker for many helpful comments. This research was funded by the ESRCTSB-BIS-NESTA as part of the ES/J008427/1 grant on Skills, Knowledge, Innovation, Policy and Practice (SKIPPY). The data used in this publication were made available to us by the German Socio Economic Panel Study (GSOEP) at the German Institute for Economic Research (DIW), Berlin. Neither the original collectors of the data nor the Archive bears any responsibility for the analyses or interpretations presented here. The usual caveat applies.

${ }^{*}$ Corresponding author

Email addresses: m.binder@berlin.bard.edu (Martin Binder), a.coad@sussex.ac.uk (Alex Coad)
} 


\section{Introduction}

With society undergoing rapid change in its forms of work organization, entrepreneurs and the self-employed have come to the attention of researchers. Small, high-growth firms are one important driver for employment growth (Henrekson and Johansson, 2010) and policymakers are interested in fostering a more entrepreneurial society (Storey, 1994). But what about entrepreneurs and the self-employed themselves? There is much research interest in which factors make for a successful entrepreneur (Sarasvathy, 2004), but we are also interested in what the outcomes of successful entrepreneurship are: despite the self-employed usually earning less than their employed counterparts (Hamilton, 2000), large numbers of individuals find becoming their own boss highly attractive (Blanchflower, 2004). One common explanation for this is the high degree of autonomy and work satisfaction individuals can derive from self-employment (Benz and Frey, 2008a).

This paper expands on this latter theme. High work satisfaction for the self-employed has often been interpreted to mean that the self-employed are happier with their lives, although strictly speaking, the evidence on the self-employment-happiness relationship is considerably weaker and more mixed than with work satisfaction. Many studies confirm a high work satisfaction of the self-employed, but only few find a direct relationship with life satisfaction/happiness measures (e.g., Binder and Coad, 2013a). As has been argued in previous work on the topic, one explanation for this puzzling finding could lie in a crowding-out phenomenon: self-employed who are much happier with their work than the employed spend considerably more time with their job thus crowding-out other important domains of life (such as leisure time) and leading in sum to a neutral effect on overall life satisfaction (ibid.). An alternative explanation could lie in self-employed individuals being a heterogeneous group of people and only certain forms of self-employment might be conducive for subjective wellbeing, for example when individuals pursue entrepreneurial opportunities as opposed to being forced into self-employment to avoid unemployment (Reynolds et al., 2005; Block and Koellinger, 2009; Binder and Coad, 2013a).

In the present study we explore these questions with a large German household panel data set and ask whether the self-employed in Germany are more satisfied with work and life than their employed counterparts. Given the need for high-quality replication studies 
(Aguinis and Edwards, 2014; Evanschitzky et al., 2007), we replicate and substantively extend a study from the UK with German data (Binder and Coad, 2013a). We mainly rely on matching techniques (see, e.g., Lechner, 2009; Böckerman and Ilmakunnas, 2009; Oakes and Kaufman, 2006), in order to replicate the aforementioned study faithfully, but also because multivariate regression modeling gives no consideration to the distribution of covariates in the treatment versus control groups. Unless there is substantial overlap in the two sets of covariate distributions, multivariate regression estimates rely heavily on extrapolation, and can be misleading (Imbens, 2004; Ichino et al., 2008, pp. 312-313). Matching estimators are preferable because an appropriate control group is established. Another advantage of matching methods is that they avoid assumptions on functional forms.

In addition, our paper goes beyond previous work by contributing novel insights to the literature in a variety of ways: in order to explore the crowding-out hypothesis, we analyze to what extent self-employment impacts different domains of life of the self-employed, making use of the rich data set at hand. We thus take a broader "life domain view" and look into whether going into self-employment has an impact on life domains ranging from work satisfaction to satisfaction with health, household income, leisure time, standard of living, dwelling, housework and family life. With this focus on different domain satisfaction as a complement to life satisfaction as dependent variable, our paper is related to some recent papers that try to unpack life satisfaction into its constituent parts (van Praag et al., 2003; Powdthavee, 2012; Binder and Coad, 2013a). Analysing the impact of self-employment on different domain satisfactions is also worthwhile because these domain measures tend to be more reliable than global judgements of overall life satisfaction (Schwarz and Strack, 1999; Krueger and Schkade, 2008).

We also explore the self-employment-happiness nexus by distinguishing whether individuals pursue self-employment in order to exploit new business opportunities versus individuals who become self-employed out of sheer necessity in order to escape unemployment. It has been shown in previous work that this distinction can account for differences in life satisfaction of the self-employed, with opportunity pursuing entrepreneurs being significantly more happy than their employed peer and necessity entrepreneurs not being so Binder and Coad (2013b). Finally, we also look into the question whether company size, autonomy of one's 
job as well as the industry in which one works have a bearing on work and life satisfaction of our German sample.

Our paper proceeds in the following way: we first give a short overview over the pertinent literature background in Section 2 and proceed then to our analysis in Section 3, where we discuss data set and variables, present our results as well as a number of extensions. We conclude in Section 4.

\section{Literature background}

Subjective well-being (SWB, or synonymously "happiness") has been intensively studied in recent years and is linked to a range of determinants that seem to reliably influence it the world over (Frey and Stutzer, 2002, 2005; Dolan et al., 2008; Graham, 2009; Layard et al., 2012): opportunities for gainful employment and work organization are one of its most important determinants. But the relationship between subjective well-being and selfemployment $^{1}$ is complicated: if we measure subjective well-being as job/work satisfaction, findings are consistently positive. Multiple studies report "rather robust finding[s] across the nations on which data are available" that self-employment is related to higher overall job satisfaction (Blanchflower, 2004), this being the case in the US (Blanchflower and Oswald, 1998; Kawaguchi, 2008) and other OECD countries (Blanchflower, 2000; Blanchflower et al., 2001; Clark et al., 2008).

High job satisfaction is thus one principal return to entrepreneurship, despite a number of drawbacks such as lower monetary returns to self-employment (Hamilton, 2000), ${ }^{2}$ higher variability of returns (Praag and Versloot, 2007), fewer fringe benefits (Storey, 1994, Ch. 6), longer working hours (Ajayi-obe and Parker, 2005; Hyytinen and Ruuskanen, 2007) and higher levels of stress (Andersson, 2008; Schieman et al., 2006; Parasuraman and Simmers, 2001).

\footnotetext{
${ }^{1}$ We (and much of the literature) use the terms self-employment and entrepreneurship interchangeably for ease of reference (on this practice see also Carter, 2011). Some might consider there to be differences between entrepreneurship and self-employment, e.g. in terms of innovation, growth ambition, etc. Bear in mind that when talking about entrepreneurship in this paper, we refer to self-employment.

${ }^{2}$ Typical returns to self-employment are lower than compared to earnings for being employed, but there are issues of underreporting of returns of the self-employed for tax reasons, as well as other considerations that warrant further research on this front (Carter, 2011).
} 
Positive overall job satisfaction despite some objectively worse outcomes of self-employment has been explained with reference to "procedural utility" that the self-employed derive from their work (Benz and Frey, 2008a,b): self-employed individuals obtain satisfaction from leading an independent lifestyle and "being their own bosses". Hundley (2001) finds that the self-employed are more satisfied with their jobs mainly because of greater autonomy, but also because of more flexibility, skill utilization and, to some extent, higher (perceived) job security (see also, Carter et al., 2003; Feldman and Bolino, 2000; Parasuraman and Simmers, 2001). ${ }^{3}$ The autonomy of being self-employed here is probably the most consistent explanation for higher job satisfaction and finds corroboration through self-determination theory (Deci and Ryan, 2000): the need for autonomy and its satisfaction were shown in psychological research to be robustly related to better psychological functioning and well-being. Such an explanation would also be consistent with findings that employees have a lower job satisfaction in large firms compared to small firms (Idson, 1990; Benz and Frey, 2008a). ${ }^{4}$

But one should also be aware of the fact that there remain issues of reverse causality regarding the relationship between job satisfaction and self-employment: Kawaguchi (2008) observes that job quitting tends to follow low job satisfaction and Noorderhaven et al. (2004) find a positive association of the levels of "dissatisfaction with life" observed in a society with high self-employment rates. This means that low satisfaction (with job or life) could "push" individuals into self-employment (but see the negative evidence for this in Schjoedt and Shaver, 2007). At least on the macro level, an association with low satisfaction and selfemployment could also be explained with reference to necessity entrepreneurship, i.e. large numbers of individuals in poor countries are forced into self-employment to escape unemployment and there would be no reason to suspect that these individuals would experience higher well-being from their situation (compare also Bianchi, 2012).

The above findings notwithstanding, satisfaction with work (as analyzed in most studies as proxy for well-being) does not equal life satisfaction, but is merely one life domain amongst

\footnotetext{
${ }^{3}$ Interestingly, the latter has been identified to decrease job satisfaction in a recent study of European self-employment (Millán et al., 2013).

${ }^{4}$ Also, the positive effect of being self-employed on job satisfaction diminishes markedly when taking into account the heterogeneity of the control group of the employed in terms of the size of the firm they are working in Benz and Frey (2008a, p. 374).
} 
others, which all together determine an individual's life satisfaction (van Praag et al., 2003; Schjoedt and Shaver, 2007; Powdthavee, 2012; Binder and Coad, 2013b). If self-employment would contribute positively to work satisfaction but decrease satisfaction with other domains of life (e.g., with the financial situation or with leisure time), it is not prima facie clear what the net effect on life satisfaction would be (see also McAdams et al., 2012, on this "bottomup" approach as to how domain satisfactions contribute to life satisfaction). As such, taking job satisfaction results and arguing that individuals derive higher (overall) well-being from being self-employed seems to be a sleight-of-hand that might distract from the direct analysis of the relationship between self-employment and life satisfaction.

When looking for evidence for the impact of self-employment on life satisfaction proper, the picture becomes much more ambiguous (Dolan et al., 2008, p. 101): Blanchflower and Oswald (1998) report for cross-sectional data from the US that young self-employed are happier, and in a similar vein Craig et al. (2007) provide some evidence for this relationship from Australian small businesses. Looking at European countries, Blanchflower (2004) fails to find overly strong effects of self-employment on life satisfaction (only for subgroups, selfemployment is significantly related to life satisfaction; and strongly depending on the data set used). Evidence about this relationship is scant (Harbi and Grolleau, 2012; Andersson, 2008, p. 231).

The empirically weak association between self-employment and life satisfaction might be a result of the above-mentioned domain view of well-being. Highly satisfied with their jobs, the self-employed ignore other important life domains and turn out to be less satisfied in those, leading to an overall sketchy association of self-employment and global well-being. But at the same time, it is also clear that the self-employed are a rather heterogeneous group (Santarelli and Vivarelli, 2007) and only subsets of self-employed are indeed happier with their life overall. This hypothesis has been pursued by Binder and Coad (2013a), who distinguished between what has been called necessity and opportunity self-employment (Reynolds et al., 2005), and argued that individuals who seek self-employment out of necessity and to avoid unemployment might not profit at all from becoming self-employed (Fuchs-Schündeln, 2009). Only individuals who voluntarily go into self-employment to pursue entrepreneurial opportunities can be conjectured to enjoy the entrepreneurial life-style and enjoy procedu- 
ral utility from becoming self-employed. ${ }^{5}$ With BHPS data, it could indeed be shown that opportunity self-employed were significantly more satisfied with their life overall than their employed counterparts (Binder and Coad, 2013a, but a similar difference could not be established for the necessity case). ${ }^{6}$ From a theoretical point of view, this finding is also in line with self-determination theory that argues that individuals only derive well-being benefits from autonomous action, whereas being forced into self-employment seems to be a paradigmatic case of the opposite (even if the self-employed afterwards enjoy some autonomy in their job itself).

Given these two observations about different types of self-employment as well as the underresearched question of domain satisfactions of the self-employed in domains other than work satisfaction, our empirical approach will attempt to fill these gaps and analyze the satisfaction of the self-employed in different life domains as well as separating the self-employed into a group of opportunity and a group of necessity entrepreneurs.

\section{Analysis}

\subsection{Data set and variables}

We use the German Socio-Economic Panel (SOEP) longitudinal data set which contains household and individual level micro-data on social and economic change in Germany. The data set now comprises around 12,000 households (approximately 20,000 persons). It has started out in 1984 with 6,000 households which were selected following multistage random sampling, aiming at a nationally representative selection of German households (for more information see Wagner et al., 2007; Haisken-DeNew and Frick, 2005).

We focus mostly on working individuals, tracking those individuals who transition from either employment or unemployment into self-employment. We omitted those cases where individuals did not report our main variables, and effectively have an unbalanced panel sample

\footnotetext{
${ }^{5}$ Cooper and Artz (1995) found that entrepreneurs with initially high expectations for their business venture performance turned out to be more satisfied than other entrepreneurs, suggesting that these more satisfied individuals have some more optimistic personality traits that influence their subsequent job satisfaction. Wether there are certain personality traits that facilitate self-employment and the related satisfaction derived from it is still a matter of active research (e.g. Caliendo and Kritikos, 2011).

${ }^{6}$ Block and Koellinger (2009) find a similar difference in terms of satisfaction with the startup, i.e. necessity entrepreneurs do not receive satisfaction from what they are forced to be doing.
} 


\begin{tabular}{|c|c|c|c|c|c|c|c|c|c|}
\hline & \multicolumn{3}{|c|}{ employed } & \multicolumn{3}{|c|}{ self-employed } & \multicolumn{3}{|c|}{ unemployed } \\
\hline & mean & sd & count & mean & sd & count & mean & sd & count \\
\hline \multicolumn{10}{|l|}{ Satisfaction With... } \\
\hline Life Today & 7.12 & 1.60 & 96941 & 7.10 & 1.72 & 12355 & 6.44 & 2.03 & 44216 \\
\hline Work & 7.04 & 1.96 & 95797 & 7.28 & 2.00 & 12204 & 3.76 & 3.34 & 4009 \\
\hline Health & 7.01 & 1.96 & 96770 & 7.06 & 2.01 & 12335 & 6.04 & 2.40 & 44133 \\
\hline Household Income & 6.52 & 2.04 & 96069 & 6.51 & 2.29 & 12266 & 5.55 & 2.58 & 43724 \\
\hline Leisure Time & 6.45 & 2.15 & 96677 & 5.63 & 2.55 & 12306 & 7.42 & 2.13 & 44006 \\
\hline Dwelling & 7.72 & 1.86 & 96620 & 7.93 & 1.87 & 12322 & 7.53 & 2.06 & 44047 \\
\hline Housework & 6.69 & 1.98 & 64917 & 6.44 & 2.16 & 7629 & 6.56 & 2.01 & 37634 \\
\hline Family Life & 7.70 & 1.93 & 32850 & 7.60 & 2.06 & 4576 & 7.69 & 2.09 & 13445 \\
\hline $\log ($ income $)$ & 10.03 & 0.43 & 96941 & 10.36 & 0.60 & 12355 & 9.69 & 0.56 & 44216 \\
\hline \multicolumn{10}{|l|}{ Marriage dummies } \\
\hline married & 0.62 & 0.49 & 96941 & 0.68 & 0.47 & 12355 & 0.72 & 0.45 & 44216 \\
\hline separated & 0.02 & 0.14 & 96941 & 0.03 & 0.16 & 12355 & 0.02 & 0.14 & 44216 \\
\hline spouseaway & 0.00 & 0.03 & 96941 & 0.00 & 0.00 & 12355 & 0.00 & 0.03 & 44216 \\
\hline \multicolumn{10}{|l|}{ Household type dummies } \\
\hline 1-Pers. $-H H$ & 0.13 & 0.34 & 96941 & 0.13 & 0.34 & 12355 & 0.11 & 0.31 & 44216 \\
\hline Couple Without Children & 0.29 & 0.46 & 96941 & 0.29 & 0.46 & 12355 & 0.40 & 0.49 & 44216 \\
\hline Single Parent & 0.04 & 0.20 & 96941 & 0.03 & 0.18 & 12355 & 0.06 & 0.23 & 44216 \\
\hline Couple With Children LE 16 & 0.25 & 0.43 & 96941 & 0.27 & 0.44 & 12355 & 0.17 & 0.38 & 44216 \\
\hline Couple With Children GT 16 & 0.19 & 0.39 & 96941 & 0.16 & 0.37 & 12355 & 0.16 & 0.37 & 44216 \\
\hline Couple With Children LE and GT 16 & 0.07 & 0.26 & 96941 & 0.08 & 0.27 & 12355 & 0.06 & 0.24 & 44216 \\
\hline Multiple Generation-HH & 0.02 & 0.12 & 96941 & 0.01 & 0.11 & 12355 & 0.02 & 0.16 & 44216 \\
\hline Other Combination & 0.01 & 0.10 & 96941 & 0.02 & 0.12 & 12355 & 0.02 & 0.12 & 44216 \\
\hline Number of Persons in $\mathrm{HH}$ & 2.83 & 1.25 & 96941 & 2.85 & 1.25 & 12355 & 2.76 & 1.33 & 44216 \\
\hline d_disabled & 0.05 & 0.22 & 96941 & 0.03 & 0.18 & 12355 & 0.21 & 0.41 & 44216 \\
\hline gender & 0.33 & 0.47 & 96941 & 0.27 & 0.44 & 12355 & 0.64 & 0.48 & 44216 \\
\hline age & 41.62 & 10.78 & 96941 & 46.24 & 10.60 & 12355 & 50.23 & 13.01 & 44216 \\
\hline $\operatorname{age}^{2}$ & 133.52 & 151.34 & 96941 & 112.50 & 149.41 & 12355 & 189.13 & 156.33 & 44216 \\
\hline 1 a inadeq. compl. & 0.01 & 0.11 & 96941 & 0.01 & 0.07 & 12355 & 0.05 & 0.22 & 44216 \\
\hline $1 b$ elementary & 0.06 & 0.23 & 96941 & 0.03 & 0.16 & 12355 & 0.17 & 0.37 & 44216 \\
\hline 1c basic voc. & 0.25 & 0.43 & 96941 & 0.21 & 0.41 & 12355 & 0.36 & 0.48 & 44216 \\
\hline $2 b$ middle gen. & 0.02 & 0.15 & 96941 & 0.02 & 0.13 & 12355 & 0.04 & 0.19 & 44216 \\
\hline 2a middle voc. & 0.31 & 0.46 & 96941 & 0.26 & 0.44 & 12355 & 0.22 & 0.42 & 44216 \\
\hline 2c-gen: hi gen . & 0.01 & 0.11 & 96941 & 0.03 & 0.17 & 12355 & 0.01 & 0.11 & 44216 \\
\hline 2c_voc: hi voc. & 0.08 & 0.27 & 96941 & 0.08 & 0.27 & 12355 & 0.04 & 0.19 & 44216 \\
\hline 3a low tert. & 0.08 & 0.27 & 96941 & 0.10 & 0.30 & 12355 & 0.03 & 0.18 & 44216 \\
\hline $3 b$ high tert. & 0.18 & 0.38 & 96941 & 0.28 & 0.45 & 12355 & 0.08 & 0.26 & 44216 \\
\hline subj. health & 3.60 & 0.83 & 96941 & 3.62 & 0.84 & 12355 & 3.10 & 1.01 & 44216 \\
\hline d_German & 0.92 & 0.28 & 96941 & 0.94 & 0.23 & 12355 & 0.86 & 0.34 & 44216 \\
\hline Observations & 96941 & & & 12355 & & & 44216 & & \\
\hline
\end{tabular}

Table 1: Descriptive statistics, broken down by employment type.

of 270, 094 observations spanning 1997 to 2010, due to the subjective health variable only being asked quite late into the panel as well as the self-employment variable being changed in 1997. A summary overview of the variables used in subsequent analysis is given in Table 1 , where we split the sample into employed, self-employed and unemployed individuals.

For our analysis, the main dependent variables are life satisfaction, work satisfaction as well as a number of other domain satisfactions. The SOEP has contained a life satisfaction question from 1984 on. Respondents are asked how satisfied, all in all, they are with their 
life at the moment ("today"). The answer is given on an ordinally scaled, eleven point Likert scale ranging from 0 (lowest satisfaction) to 10 (highest satisfaction). This measure has been extensively used in the literature on subjective well-being. The validity of such subjective well-being measures has been established within the psychological and economic literature (Diener et al., 1999; Helliwell and Wang, 2012; Layard et al., 2010), and subjective well-being measures correlate in the expected directions with a number of objective factors such as e.g. emotional expressions like smiling (Fernandez-Dols and Ruiz-Belda, 1995). Individuals are also able to (ordinally) compare and assess other individuals' happiness, for example when individuals' self-reports are correlated with reports of friends and family (Sandvik et al., 1993; Diener and Lucas, 1999). As regards these measures' reliability, the consensus is that they quite reliably measure the intended individual well-being. The test-retest reliability of subjective well-being constructs lies between 0.5 and 0.7 (over two weeks, see Krueger and Schkade, 2008). ${ }^{7}$ We also look at other domain satisfactions, ranging from work satisfaction (which measures the overall satisfaction with the job) to satisfaction with health, household income, leisure time, standard of living, dwelling, housework and family life. These are measured on the same scale as life satisfaction but many domain satisfactions were only elicited in fewer waves. Moreover, while life satisfaction was available for our full sample (for the FE regressions), work satisfaction, for instance, was mostly reported by employed individuals and very few unemployed individuals (FE regression sample size of 159,920). Empirically, domain satisfaction judgements turn out to be more reliable than life satisfaction judgements (Schwarz and Strack, 1999; Krueger and Schkade, 2008), with reliabilities from 0.68 to 0.74 as opposed to 0.54 for the more global life satisfaction (Krueger and Schkade, 2008, p. 1838). This does make sense from a theoretical point of view if one considers that individuals can more easily assess their life in a single domain as opposed to somehow aggregating their domain satisfaction judgments into a comprehensive well-being assessment (it is likely that such life satisfaction assessments are arrived at via heuristics, for example by recourse to recent salient events or using current mood as a proxy, see Schwarz and Strack,

\footnotetext{
${ }^{7}$ We treat this measure as cardinal at various instances throughout our analysis since it was shown in the literature that this does not alter findings substantially and it allows us to use a fixed-effects regression framework Ferrer-i-Carbonell and Frijters (2004).
} 
1999).

Our main independent variable is self-employment and other labor-force statuses as control categories. We count individuals as self-employed who work full-time and are selfemployed (10,194 obs.), freelance (4,766 obs.) or help in their family business (642 obs.). We have excluded the category of self-employed farmers (685 obs.) because of difficulties in comparing this work with other jobs (Hundley, 2001, p. 299). Beside unemployment (we have included as unemployed those who report their labor-force status as "not working unemployed" as well as those who report to be "non-working"), employment (we focus on individuals working full-time) and self-employment, we have added maternity-leave, retirement, being in education and completing one's civil or military service in the fixed-effects regressions. In our main analysis, however, we focus only on these individuals who either switch from (un)employment to self-employment (treatment group) or those who remain in (un)employment (control group).

Our measure of income is equivalized (with the International Experts' scale) and deflated post-government household income (i.e. income after taxes and government transfers; see similarly Headey et al., 2004; D'Ambrosio and Frick, 2007). In line with the literature, we use the logarithm of the income measure as a regressor in our analysis, assuming that a given change in the proportion of income leads to the same proportional change in well-being (Stevenson and Wolfers, 2008; Layard et al., 2008).

As a measure for an individual's health, we use self-rated health. Self-rated health is a subjective health indicator, ordinally scaled on a five point Likert scale ranging from 1 ("very good") to 5 ("bad") and a dummy variable for being disabled. Lastly, we have included a number of ordinary control variables (see Table 1) which comprise gender, different marital statuses, household size and composition variables, age, and age ${ }^{2}$ (the squared difference between age and mean-age to be precise). We control for year effects and regions (German "Bundeslaender" and East vs. West-Germany) but do not report this to conserve space. Also included is an educational control variable, viz. an individual's highest level of education, as measured by the CASMIN scale. This is measured by converting the reported categories, ranging from zero ("In School") to nine ("Higher Tertiary Education"), into a series of dummy variables (Table 7 in the Appendix shows the contemporaneous correlations of our 
main variables).

\subsection{Main results: work and life satisfaction}

Are the self-employed in Germany more satisfied with their work and life than other individuals? Neither the simple comparison of means (Table 1) nor our baseline fixed-effects regressions (see Table 2, column 1) would suggest that the self-employed are happier with their lives than the control group. However, they are more satisfied with their work $\left(0.30^{* * *}\right)$. To compare the effect size of self-employment consider the strong negative effect $\left(-2.58^{* * *}\right)$ of unemployment on work satisfaction (where reported, see Table 2, column 2) and life satisfaction $\left(-0.30^{* * *}\right){ }^{8}$ These findings are typical for most of the literature, as are many of the coefficients for our control variables (we refrain from further discussing these here to conserve space, but compare Dolan et al., 2008; Layard et al., 2012).

Our matching estimates of becoming self-employed on subjective well-being are presented in Tables 3 and 4. Matching estimates (Rubin, 1974; Imbens, 2004; Caliendo and Kopeinig, 2008) allow us to more carefully select a control group of similar individuals to those who go into self-employment ("perfect twins" with the one exception that these control individuals do not actually get into self-employment but remain either employed or switch from unemployment into employment, Almus and Czarnitzki, 2003, p. 231). It is an econometric technique that bears similarities to an experimental setup in medical research but can be applied to observational data to recreate a "control group" that is comparable to the "treatment group" in terms of observed variables (without actually having to conduct a trial). The identifying assumption is a conditional independence assumption (CIA), which holds that the potential outcome (subjective well-being) and "treatment" participation (going into self-employment) are independent for individuals with the same exogenous characteristics, i.e. we rule out differences between the control and treatment groups in terms of unobserved variables. CIA may be a strong assumption, and moreover it cannot be verified directly but only with reference to theoretical considerations of what drives treatment and outcome. In order to justify the identifying assumption, we have selected our matching variables drawing

\footnotetext{
${ }^{8}$ Excluding "non-working" individuals and focussing only on individuals whose labor-force status is "unemployed" doubles the coefficient size to $-0.60^{* * *}$.
} 


\begin{tabular}{|c|c|c|c|c|}
\hline \multirow{2}{*}{$\log ($ income $)$} & \multicolumn{2}{|c|}{$\begin{array}{c}(1) \\
\text { life satisfaction }(\mathrm{FE})\end{array}$} & \multicolumn{2}{|c|}{$\begin{array}{c}(2) \\
\text { job satisfaction }(\mathrm{FE})\end{array}$} \\
\hline & $0.1581^{* * *}$ & $(12.99)$ & $0.1240^{* * *}$ & $(5.37)$ \\
\hline \multicolumn{5}{|l|}{ Employment dummies } \\
\hline unemployed & $-0.3022^{* * *}$ & $(-20.98)$ & $-2.5761^{* * *}$ & $(-36.48)$ \\
\hline selfemployed & 0.0168 & $(0.54)$ & $0.3021^{* * *}$ & $(6.51)$ \\
\hline maternityleave & 0.0197 & $(0.76)$ & $-0.6788^{* * *}$ & $(-6.07)$ \\
\hline retired & $-0.1738^{* * *}$ & $(-8.60)$ & $-1.4187^{* * *}$ & $(-6.33)$ \\
\hline education & 0.0227 & $(0.99)$ & $-0.5422^{* * *}$ & $(-5.26)$ \\
\hline civmilservice & -0.1072 & $(-1.07)$ & -0.3917 & $(-1.64)$ \\
\hline \multicolumn{5}{|l|}{ Marriage dummies } \\
\hline married & $0.0721^{* *}$ & $(2.72)$ & 0.0512 & $(1.27)$ \\
\hline separated & $-0.1272^{* *}$ & $(-2.77)$ & $0.1568^{*}$ & $(2.47)$ \\
\hline widowed & -0.1091 & $(-1.86)$ & 0.0712 & $(0.58)$ \\
\hline divorced & $0.1192^{* *}$ & $(2.92)$ & -0.0106 & $(-0.17)$ \\
\hline spouseaway & $1.0082^{*}$ & $(2.19)$ & $-0.9045^{*}$ & $(-2.10)$ \\
\hline \multicolumn{5}{|l|}{ Household type dummies } \\
\hline Couple Without Children & $0.1803^{* * *}$ & $(7.08)$ & -0.0418 & $(-1.05)$ \\
\hline Single Parent & $-0.0932^{* *}$ & $(-2.70)$ & 0.1023 & $(1.84)$ \\
\hline Couple With Children LE 16 & $0.1984^{* * *}$ & $(5.78)$ & 0.0752 & $(1.38)$ \\
\hline Couple With Children GT 16 & $0.0657^{*}$ & $(1.97)$ & 0.0515 & $(0.96)$ \\
\hline Couple With Children LE and GT 16 & $0.1331^{* * *}$ & $(3.52)$ & 0.0857 & $(1.42)$ \\
\hline Multiple Generation-HH & $0.1533^{* *}$ & $(2.66)$ & 0.0160 & $(0.16)$ \\
\hline Other Combination & 0.0391 & $(0.80)$ & -0.1601 & $(-1.91)$ \\
\hline Number of Persons in $\mathrm{HH}$ & -0.0076 & $(-0.80)$ & 0.0028 & $(0.17)$ \\
\hline d_disabled & $-0.1468^{* * *}$ & $(-6.73)$ & $-0.1203^{*}$ & $(-2.42)$ \\
\hline age & $-0.0035^{*}$ & $(-2.39)$ & $-0.0246^{* * *}$ & $(-9.48)$ \\
\hline $\operatorname{age}^{2}$ & $-0.0001^{*}$ & $(-2.44)$ & 0.0000 & $(0.17)$ \\
\hline \multicolumn{5}{|l|}{ Education dummies } \\
\hline (0) In School & $0.2931^{* * *}$ & $(4.40)$ & $-0.5696^{* *}$ & $(-2.84)$ \\
\hline (1b) General Elementary School & $0.1504^{* *}$ & $(2.67)$ & 0.0593 & $(0.57)$ \\
\hline (1c) Basic Vocational Qualificat. & 0.0804 & $(1.35)$ & 0.0277 & $(0.26)$ \\
\hline (2b) Intermediate General Qualif. & 0.1230 & $(1.92)$ & 0.1271 & $(1.04)$ \\
\hline (2a) Intermediate Vocational & 0.1097 & $(1.77)$ & 0.0873 & $(0.76)$ \\
\hline (2c_gen) General Maturity Certif. & 0.1244 & $(1.89)$ & $0.2926^{*}$ & $(2.16)$ \\
\hline (2c_voc) Vocational Maturity Certif. & 0.1073 & $(1.58)$ & 0.2199 & $(1.68)$ \\
\hline (3a) Lower Tertiary Education & $0.1806^{*}$ & $(2.50)$ & $0.3373^{*}$ & $(2.44)$ \\
\hline (3b) Higher Tertiary Education & 0.1235 & $(1.76)$ & $0.3243^{*}$ & $(2.34)$ \\
\hline subj. health & $0.4950^{* * *}$ & $(89.99)$ & $0.4159^{* * *}$ & $(45.68)$ \\
\hline d_EastGermany & -0.0953 & $(-1.07)$ & -0.0614 & $(-0.37)$ \\
\hline Constant & $3.9640^{* * *}$ & $(22.14)$ & $5.1243^{* * *}$ & $(15.85)$ \\
\hline Observations & 270094 & & 159920 & \\
\hline$R^{2}$ & 0.086 & & 0.074 & \\
\hline $\mathrm{F}$ & 185.5822 & & 75.4303 & \\
\hline df_r & 40475 & & 29512 & \\
\hline
\end{tabular}

Table 2: Baseline regressions.

on the subjective well-being and entrepreneurship literature (and with an eye to maintaining comparability to the study of Binder and Coad, 2013a). The second matching assumption is known as "overlap", or the "common support condition". This assumption ensures that individuals with the same characteristics have a positive probability of being either "participants" (i.e. becoming self-employed) or "nonparticipants" (staying in (un)employment). In further analysis we find considerable support for the common support condition (the methodological background of matching is further discussed in Oakes and Kaufman, 2006; Caliendo 
and Kopeinig, 2008; Binder and Coad, 2013a).

FE models such as our baseline regressions obscure the number of observations on which coefficients for treatment variables are based, and can suffer from problems of endogeneity and self-selection, as well as the lack of potential common support for treatment and control group. More reliable estimates of the impact of self-employment on subjective well-being may be gained by using matching estimates that are less prone to the aforementioned problems. In our matching analysis, we compare individuals that are similar at time point $t$ in terms of a large number of covariates of interest such as income, health etc. We then look at individuals that (1) move from being employed in $t$ to self-employment in $t+1$ and later periods, and compare them to individuals who stay employed during the three following lags. We interpret this as the "opportunity self-employment case", where individuals leave their employment to pursue innovative opportunities. We (2) contrast this case with the case where individuals are unemployed in $t$ and move to self-employment in $t+1$ and later periods. In this "necessity self-employment case", our control group are individuals who move from unemployment into employment in the subsequent lags. Obviously both cases are quite coarse operationalizations of opportunity and necessity entrepreneurship, however, it is difficult to otherwise infer the motivation for self-employment in the data set used in our analysis.

We use two different matching estimators, namely propensity-score matching (Leuven and Sianesi, 2003) and nearest-neighbour-matching (Abadie et al., 2004). Nearest neighbour matching finds a match in many dimensions simultaneously while propensity score matching collapses all covariates into one composite variable (the so-called "propensity score"). We use the same set of covariates in both cases, namely previous change in subjective wellbeing, previous subjective well-being, $\log$ (income), subjective health, being disabled, diverse marital dummies (being married, separated, divorced or widowed, having a spouse outside of Germany), gender, age, a quadratic age term, household size, dummies for education, household type, state dummies, a dummy for living in East Germany as well as year dummies.

The results look rather similar across different matching algorithms, which provides already a test of the robustness of our results (Caliendo and Kopeinig, 2008). We can see that there are actually not as many cases where individuals transition from unemployment into employment or self-employment, something that is somewhat obscured in typical regression 


\begin{tabular}{|c|c|c|c|c|c|c|}
\hline & life $\mathrm{s}$ & isfaction & & job & satisfactiol & \\
\hline $\mathrm{E}$ to $\mathrm{S}$ & vs. E to & & & E to SE vs. & to $\mathrm{E}$ & \\
\hline & ATT & Controls & Treated & \begin{tabular}{l|l} 
ATT
\end{tabular} & Controls & Treated \\
\hline $1 \mathrm{lag}$ & $0.128+$ & 60,843 & 485 & $0.436^{* * *}$ & 60,289 & 481 \\
\hline $\mathrm{SE}$ & 0.075 & & & 0.094 & & \\
\hline$t$-stat & 1.71 & & & 4.64 & & \\
\hline 2 lags & $0.173+$ & 47,312 & 308 & $0.477^{* * *}$ & 46,711 & 304 \\
\hline $\mathrm{SE}$ & 0.093 & & & 0.109 & & \\
\hline$t$-stat & 1.86 & & & 4.37 & & \\
\hline 3 lags & $0.306^{* *}$ & 36,713 & 215 & $0.488^{* * *}$ & 36,916 & 215 \\
\hline $\mathrm{SE}$ & 0.109 & & & 0.132 & & \\
\hline$t$-stat & 2.80 & & & 3.69 & & \\
\hline UE to & $\mathrm{E}$ vs. UH & $O \mathrm{E}$ & & UE to SE vs & UE to $\mathrm{E}$ & \\
\hline & ATT & Controls & Treated & \begin{tabular}{l|l}
$\mathrm{ATT}$ \\
\end{tabular} & Controls & Treated \\
\hline 1 lag & -0.044 & 1,628 & 194 & 0.140 & 1,634 & 185 \\
\hline SE & 0.135 & & & 0.178 & & \\
\hline$t$-stat & -0.33 & & & 0.79 & & \\
\hline 2 lags & -0.255 & 793 & 108 & $0.355+$ & 773 & 109 \\
\hline $\mathrm{SE}$ & 0.194 & & & 0.207 & & \\
\hline$t$-stat & -1.32 & & & 1.72 & & \\
\hline 3 lags & -0.075 & 499 & 68 & 0.236 & 491 & 65 \\
\hline $\mathrm{SE}$ & 0.217 & & & 0.269 & & \\
\hline$t$-stat & -0.35 & & & 0.88 & & \\
\hline
\end{tabular}

Table 3: Matching estimates. We use propensity score matching (PSM, Leuven and Sianesi, 2003) and report Average Treatment effects for the Treated (ATTs) with $t$-statistics. Dependent variables are same as in the baseline regressions. Key to significance levels: $+p<0.10,{ }^{*} p<0.05,{ }^{* *} p<0.01,{ }^{* * *} p<0.001$.

tables (such as Table 2). Focussing on transitions into self-employment that last for up to three consecutive years further reduces the number of cases in our data set. Since matching also discards observations that are off-support, i.e. individuals that are very different in terms of matching covariates are not compared with each other in order to avoid "comparing apples with oranges", we have to rely on a comparatively smaller number of cases. Yet matching creates a better comparable treatment and control group and thus despite a smaller sample yields significant results. Discarding the "evil twins" in favor of finding the "perfect twin" (Almus and Czarnitzki, 2003, p. 231) for each observation thus increases the explanatory power of our estimates.

In our interpretation we focus on the propensity score matching results subset: we can see that in the case of "opportunity self-employment", both work and life satisfaction of the self-employed are significantly higher than that of their employed counterparts. While the effect for work satisfaction is $0.44^{* * *}$ in lag $t+1$ and increases to $0.49^{* * *}$ in year $t+3$ (both highly significant), the effect is less pronounced but also increasing for life satisfaction (from $0.13^{+}$in year $t+1$ to $0.31^{* *}$ in year $\left.t+3\right)$. If one does pursue self-employment from the security of one's previous job and leaves employment for self-employment, there seems to be 
positive returns to work and life satisfaction for the self-employed. As self-employment is unlikely to result in higher incomes of the self-employed (except for a few exceptional cases, see Hamilton, 2000), this increased satisfaction must be due to other work related factors of self-employment, most likely the autonomy that is afforded by being one's own boss (Deci and Ryan, 2000; Feldman and Bolino, 2000; Benz and Frey, 2008a).

The necessity case is markedly different: both life satisfaction and work satisfaction show no significant change for the treatment as opposed to the control group. In the case of work satisfaction, coefficients are positive and insignificant (the exception is a positive coefficient in lag $t+2)$. In the case of life satisfaction, coefficients are negative and insignificant. We interpret this as evidence consistent with the hypothesis that pursuing self-employment to escape unemployment has no benefits in terms of work and life satisfaction for the newly selfemployed. This interpretation is consistent with the data, where the autonomy of necessity self-employed individuals is lower (t-test highly significant) than that of opportunity cases. Comparatively more individuals are in the lower categories of the autonomy variable that is present in the data set. From the point of view of self-determination theory, these results are not surprising, since being forced into self-employment is not an autonomous decision, and it can be conjectured that the necessity self-employed thus experience their new life (and lifestyle) as something they cannot strongly identify with. Our results are rendered more surprising given findings in the literature that happy individuals are more likely to pursue necessity self-employment (Krause, 2012). Such reverse causality should actually inflate the impact of necessity self-employment on subjective well-being.

From a policy point of view, being self-employed as opposed to being unemployed might certainly be preferable (in terms of individuals earning their own income). Our findings for the necessity case should not be understood to discourage self-employment as an alternative to being on welfare. However, this type of self-employment cannot be expected to be as beneficial for the self-employed as is the case for "opportunity self-employment".

We can compare our results also to the results for the British case (see Binder and Coad, 2013a) and have to conclude that both analyses yield similar estimates: in the British case as well, transitioning from employment to self-employment yields positive life satisfaction changes $\left(.17^{* *}\right.$ to $.23^{*}$ for the nearest-neighbour-matching estimator and $.11^{*}$ to $.20^{*}$ for the 


\begin{tabular}{l|cllll}
\hline \hline \multicolumn{3}{c}{ life satisfaction } & \multicolumn{3}{c}{ job satisfaction } \\
E to SE vs. E to E & \multicolumn{3}{c}{ E to SE vs. E to E } \\
\hline 1 lag & $0.241^{* *}$ & 62,998 & $0.525^{* * *}$ & 62,447 \\
SE & 0.079 & & 0.105 & \\
z-stat & 3.06 & & 5.02 & \\
2 lags & $0.176+$ & 49,737 & $0.410^{* *}$ & 49,286 \\
SE & 0.101 & & 0.125 & \\
z-stat & 1.74 & & 3.28 & \\
3 lags & $0.330^{* *}$ & 39,327 & $0.459^{* *}$ & 39,156 \\
SE & 0.117 & & 0.150 & \\
z-stat & 2.81 & & 3.05 & \\
\hline UE to SE vs. UE to E & & \\
\hline 1 lag & -0.096 & 1,912 & 0.052 & 1,882 \\
SE & 0.145 & & 0.197 & \\
$z$-stat & -0.67 & & 0.27 & \\
2 lags & $-0.373+$ & 1,067 & 0.188 & 1,058 \\
SE & 0.197 & & 0.239 & \\
$z$-stat & -1.90 & & 0.78 & \\
3 lags & -0.107 & \multirow{2}{*}{728} & 0.140 & 719 \\
SE & 0.231 & & 0.304 & \\
$z$-stat & -0.46 & & 0.46 & \\
\hline \hline
\end{tabular}

Table 4: Matching estimates. We use nearest-neighbour-matching (NNM, Abadie et al., 2004) and report Sample Average Treatment Effects (SATEs) with $z$-statistics. Dependent variables are same as in the baseline regressions. Key to significance levels: $+p<0.10,{ }^{*} p<0.05,{ }^{* *} p<0.01,{ }^{* * *} p<0.001 .4$ matches are selected for each treatment observation.

propensity score matching estimator; only two years studied; no work satisfaction results). ${ }^{9}$ We should be careful in attributing higher impact for the German case since life satisfaction in the British sample was measured on a 7-point Likert scale. Similarly, no gains in life satisfaction were found in the UK for the transition out of unemployment into self-employment. This comparison provides evidence that the British findings were not something culturally limited to the UK but might apply more broadly in Europe as well.

\subsection{Results: other life domains}

It is instructive to see whether transitioning into self-employment will impact on subjective well-being more broadly. To that matter and to explore further whether going into selfemployment does have broader effects beside the ones on an individual's work satisfaction, we look into other life domains and the individual's satisfaction with them after becoming self-employed. In Table 5, we show results similar to the analysis for work and life satisfaction (we match on the same covariates and with the same matching algorithms), but have different

\footnotetext{
${ }^{9}$ Note that matching estimates refer to total effects on subjective well-being while regression coefficients are ceteris paribus effect sizes, holding all other variables of interest constant (Oakes and Kaufman, 2006, p. 382). They should not be directly compared with each other, thus, and comparison of our results with other studies using multivariate regression is not straightforward.
} 
domain satisfactions as our dependent variables. The upper half of the table shows the results for the opportunity case while the lower half shows the necessity case. Our results here are quite striking in showing that self-employment has a quite contained impact only on few life domains. The most important results pertain to satisfaction with health and spare time. No matter what type of self-employment analyzed, the self-employed are significantly less satisfied with their spare time. The negative influence of lack of leisure time is increasing over time and even stronger for those, who are self-employed out of necessity. Here our analysis confirms previous studies that find that the self-employed find themselves in a situation that puts high demand on their time and leads to lack of leisure time (Hyytinen and Ruuskanen, 2007). Our findings here complement the literature by showing that this lack of leisure time does translate into dissatisfaction (at least in this specific domain; for a European data set, the self-employed also reported low satisfaction with their working hours, see Blanchflower, 2004, p. 48). ${ }^{10}$ While one could conjecture that lack of leisure time is something only fully committed opportunity cases would exhibit, we clearly see a similar pattern for the necessity case. Even if forced self-employment has no benefit on work and life satisfaction, the selfemployed clearly experience the negative impact of lower spare time satisfaction. Since the necessity self-employed arguably did not choose their self-employment fully voluntarily, it is even harder for them to deal with the time demands of their new career path, increasing dissatisfaction with amount of time outside their job. These findings can be related to a study of Dutch entrepreneurs whose satisfaction with leisure time was negatively associated with firm performance and positively with the motivation to combine work- and life-balance (Carree and Verheul, 2012, p. 381). Care needs to be exercised in comparing both sets of results, since the Dutch analysis is cross-sectional and it only asks what influences leisure satisfaction of entrepreneurs (no control group). It thus may be that the negative impact of self-employment on satisfaction with spare time found in our study might be mitigated for those self-employed who pursue self-employment to get a more favourable work-/life balance and be better able to organize their workload to cope with multiple responsibilities (cf. ibid.).

\footnotetext{
${ }^{10}$ The opposite pattern was found for unemployment, where the unemployed exhibited higher satisfaction with their amount of leisure time in a British sample (Powdthavee, 2012).
} 


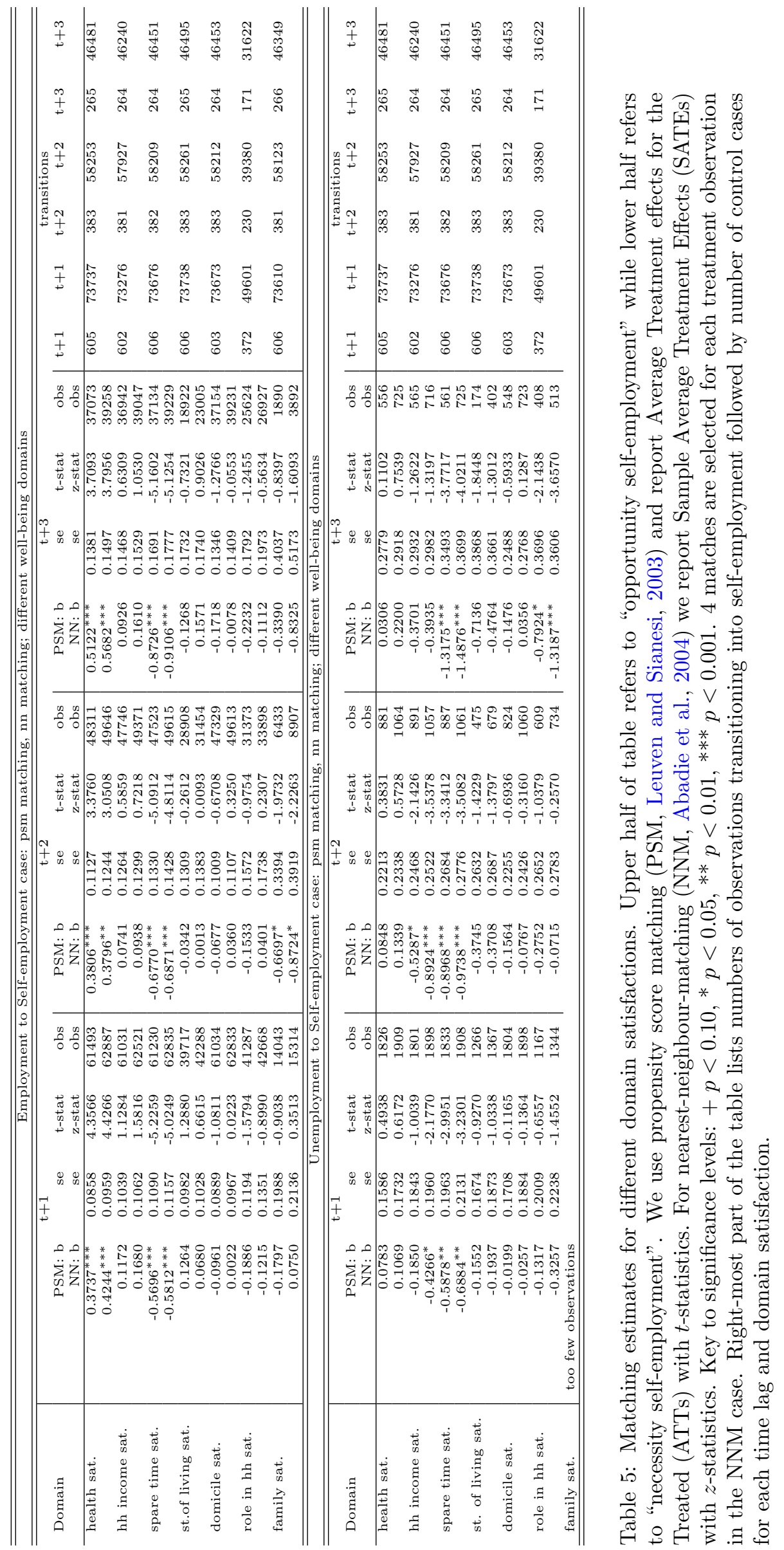


A second finding of note pertains to health satisfaction, which is positively impacted by going into opportunity self-employment (but not going into necessity self-employment). While one can conjecture that both types of self-employment have positive autonomy as their result compared to the typical employment situation, there seems to be more associated with the voluntary self-employment case, in that it seems beneficial not only for an individual's mental health (subjective well-being) but also for the individual's self-rated satisfaction with overall health. If the voluntary entrepreneurial pursuit thus also positively impacts on the selfemployed's health, this would constitute another benefit of entrepreneurship beyond possible material gain.

We have to be careful in interpreting positive health satisfaction as positive health, however. A study on Swedish self-employed did similarly find that the self-employed report themselves under less mental strain, while at the same time exhibiting more mental health problems such as tiredness (Andersson, 2008). An alternative explanation for this finding might thus lie in systematic personality differences between individuals who voluntarily pursue self-employment as opposed to those who do so involuntarily. If this is the case, satisfaction with health and life might be driven by this personality and not be a result of opportunity employment per se. It could be conjectured, for example, that more extravert individuals are more confident and thus more likely to pursue self-employment and would simultaneously rate themselves more positively in terms of health and well-being. This alternative explanation, while prima facie plausible, would be difficult to reconcile with the fact that satisfaction in other domains of life of the self-employed does not exhibit a systematically higher score for the opportunity self-employed. Further research might explore these findings in the health domain (preferably measured via objective indicators).

Our results are consistent with other research on life domains: ${ }^{11}$ the high importance of health, job and leisure time (in that order of importance) was also found in an analysis of the overall contribution of life domains to life satisfaction (van Praag et al., 2003). In extension of these results, we can, however, see a marked asymmetry between opportunity

\footnotetext{
${ }^{11}$ Our results cannot confirm the finding that self-employment creates work-home-conflict, e.g. by decreasing family satisfaction (this was found by Parasuraman and Simmers, 2001): while the coefficient for family satisfaction is negative in our sample as well, in most cases it is not statistically significant.
} 
and necessity self-employment over the different life domains analyzed: while the opportunity self-employed profit in work and health domains and suffer from lack of spare time (which could explain the moderate net gain in overall life satisfaction), the necessity self-employed profit from their self-employment in none of the life domains yet suffer from all the drawbacks (of negative spare time satisfaction).

\subsection{Results: robustness tests}

Given that autonomy is likely to be an important driver for our results, it makes sense to unpack this relationship further. We have thus analyzed for our sample whether the autonomy of one's occupation as well as the company size and industry type one works in have an impact on work and life satisfaction. In order to analyze this further, the SOEP data set provides information on the autonomy of an individual's type of work via a variable that distinguishes autonomy levels inter alia based on task descriptions, vocational training, responsibilities and company size for civil servants, workers and employees and the self-employed. It distinguishes five regular autonomy levels plus the lowest level of apprenticeship (encompassing also interns and trainees). Low autonomy levels are related to manual workers, whereas manager and freelance academics are in the highest autonomy level group. Self-employed individuals are categorized into autonomy levels 3 to 5 depending on the number of employees they have.

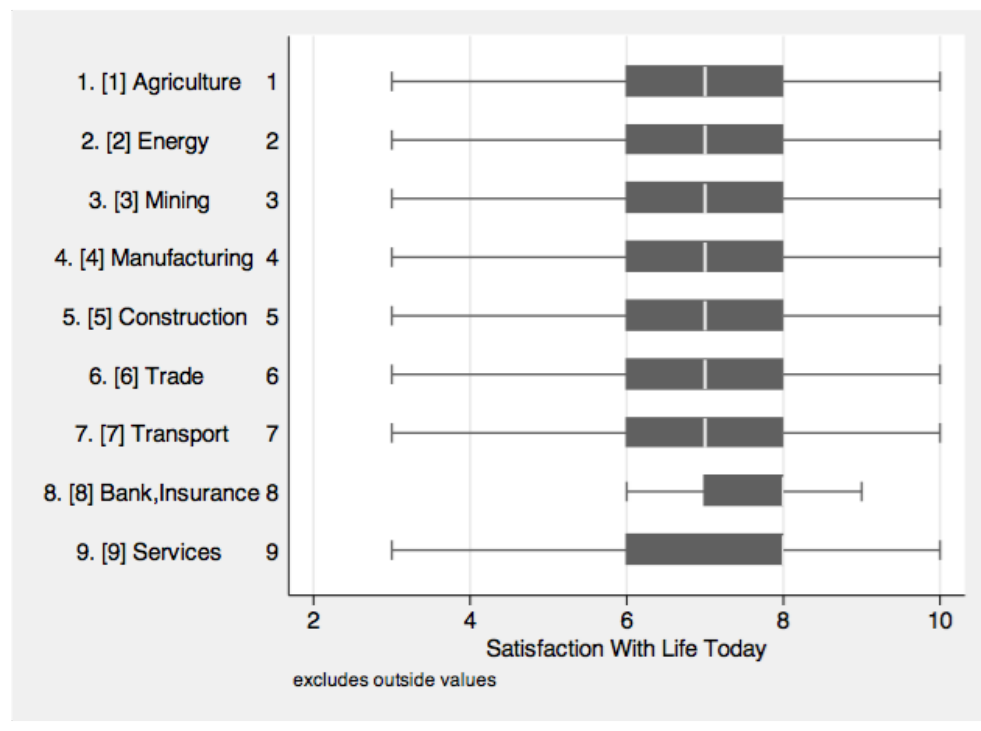

Figure 1: Box plot of life satisfaction by 1-digit industry type.

Company size for employed and self-employed individuals is available in our data set and 
offers a coarse division into the size categories of less than 20 core employees (our control category), 20 to 200, 200 to 2000 and more than 2000 employees. There is also the category of being self-employed with no other employees. The SOEP further contains 1 digit industry codes for individuals that are working, ranging from Agriculture to the Service industry (the latter of which we use as base category).

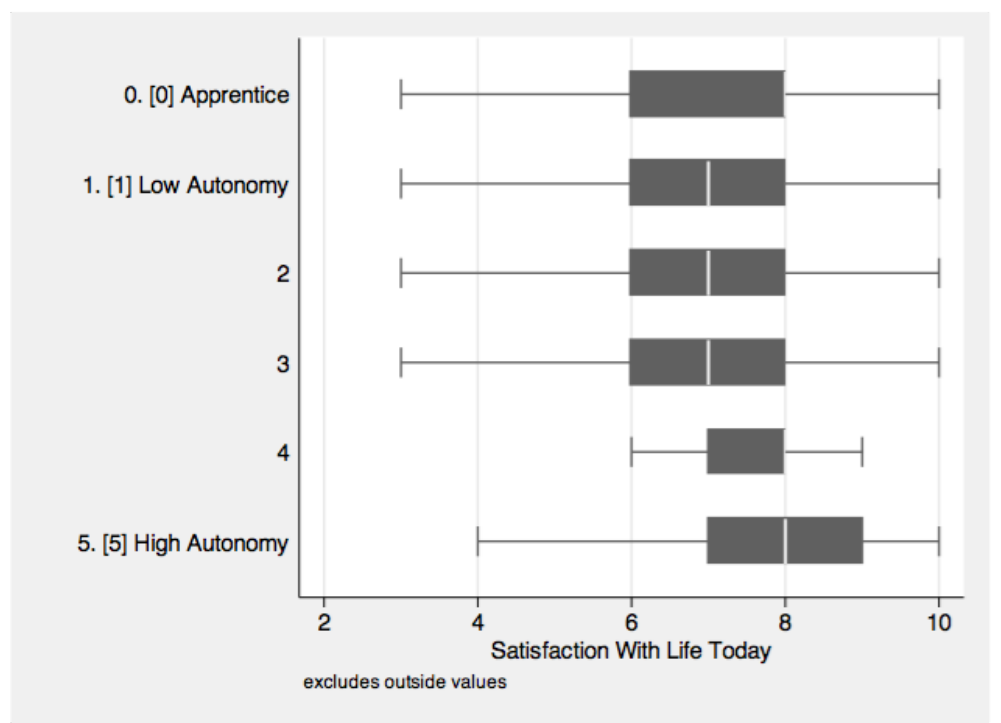

Figure 2: Box plot of life satisfaction by level of autonomy.

As a first orientation, we present box plots of life satisfaction for our sample group by industry type (on the one digit level, see Figure 1), by autonomy categorization (see Figure 2) as well as by company size (Figure 3). These box plots reveal few systematic life satisfaction differences for industry type with the exception of higher median life satisfaction in Banking/Insurance and Service industries. They also reveal higher median life satisfaction for the two highest autonomy categories (and somewhat surprisingly for the lowest, i.e. apprenticeship). In these raw data, we also find that median life satisfaction is highest in extremely big companies.

We have thus repeated our multivariate regression for life and work satisfaction and added the three variables as further control variables. The results are depicted in Table 6, where we only report the coefficients for company size (company size of less than 20 employes is the omitted reference category), autonomy (we use lowest autonomy level as baseline category, instead of the apprentice category) and industry type (with "Services" as omitted baseline 


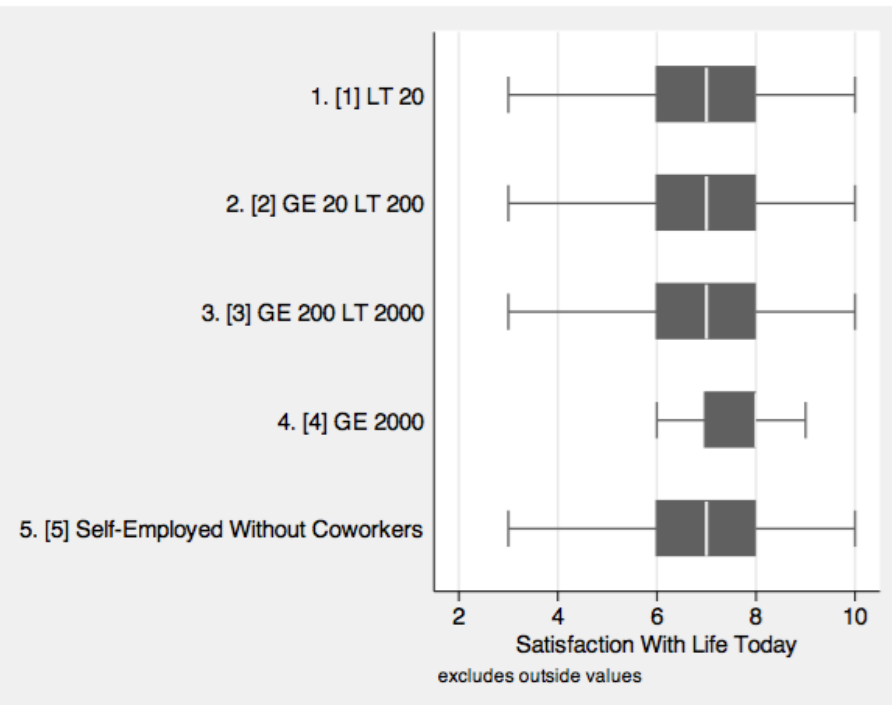

Figure 3: Box plot of life satisfaction by company size.

category). For industry types, we find no effect on life satisfaction and only few industries relate negatively to work satisfaction (as compared to the control group of Services), namely manufacturing, construction and trade. With the other two variables, we find clear associations for both work and life satisfaction. Higher autonomy is beneficial for both work and life satisfaction, increasing with autonomy level. Interestingly, compared to the low autonomy level reference category, we find a positive impact of apprenticeship for life satisfaction. With company size, we find positive coefficients also for both life and work satisfaction for medium and large companies. These findings are surprising as a reverse relationship is usually found in the literature (e.g., Benz and Frey, 2008a; Idson, 1990): it is typically argued that smaller companies offer better working conditions and more autonomy to their employees than larger companies, thus leading to higher work satisfaction for employees in smaller firms. Why this is not the case here warrants further research (the effect is not driven by the self-employed but persists when redoing the regressions only for employed individuals).

Finally, note that life satisfaction is negatively impacted for those individuals who are selfemployed with no coworkers, maybe because these also represent necessity self-employment. Alternatively, a driver of well-being for the self-employed (beside autonomy) is being in charge of a company. The latter has been already observed in the literature (Blanchflower, 2004, pp. 55-57) and might also account for the heterogeneous results regarding the life satisfaction 
self-employment relationship.

\begin{tabular}{|c|c|c|c|c|}
\hline \multirow{2}{*}{ Industry dummies (Services as omitted baseline category) } & \multicolumn{2}{|c|}{ life satisfaction (FE) } & \multicolumn{2}{|c|}{ job satisfaction $(\mathrm{FE})$} \\
\hline & & & & \\
\hline Agriculture & -0.0598 & $(-0.82)$ & 0.0773 & $(0.65)$ \\
\hline Energy & -0.0950 & $(-1.31)$ & 0.0081 & $(0.06)$ \\
\hline Mining & 0.0396 & $(0.29)$ & -0.1610 & $(-0.71)$ \\
\hline Manufacturing & 0.0480 & $(1.69)$ & $-0.1105^{*}$ & $(-2.47)$ \\
\hline Construction & 0.0174 & $(0.57)$ & $-0.1345^{* *}$ & $(-2.91)$ \\
\hline Trade & -0.0102 & $(-0.30)$ & $-0.1986^{* * *}$ & $(-3.92)$ \\
\hline Transport & -0.0517 & $(-1.12)$ & -0.0802 & $(-1.19)$ \\
\hline Bank,Insurance & 0.0279 & $(0.41)$ & 0.0304 & $(0.37)$ \\
\hline \multicolumn{5}{|l|}{ Autonomy dummies (Low Autonomy (level 1) as baseline) } \\
\hline Apprentice & $0.1775^{*}$ & $(1.97)$ & 0.1642 & $(1.02)$ \\
\hline Low Autonomy (level 2) & $0.0525^{*}$ & $(2.02)$ & $0.1341^{* * *}$ & $(3.59)$ \\
\hline 3 & $0.1500^{* * *}$ & $(4.97)$ & $0.3057^{* * *}$ & $(7.04)$ \\
\hline 4 & $0.1975^{* * *}$ & $(5.82)$ & $0.4517^{* * *}$ & $(9.27)$ \\
\hline High Autonomy (level 5) & $0.2507^{* * *}$ & $(5.64)$ & $0.5948^{* * *}$ & $(9.49)$ \\
\hline \multicolumn{5}{|l|}{ Company size dummies (LT 20 employees as baseline)) } \\
\hline$G E 20 L T 200$ & $0.0453^{*}$ & $(2.00)$ & 0.0638 & $(1.81)$ \\
\hline GE $200 L T 2000$ & $0.0816^{* *}$ & $(3.10)$ & $0.1691^{* * *}$ & $(4.00)$ \\
\hline GE 2000 & $0.1229^{* * *}$ & $(4.37)$ & $0.2193^{* * *}$ & $(4.93)$ \\
\hline Self-Employed Without Coworkers & $-0.1003^{*}$ & $(-2.27)$ & 0.0279 & $(0.47)$ \\
\hline 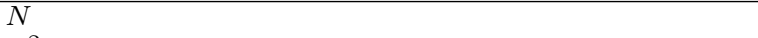 & 104338 & & 103139 & \\
\hline$R^{2}$ & 0.077 & & 0.047 & \\
\hline $\mathrm{F}$ & 81.2399 & & 34.4777 & \\
\hline df_r & 19912 & & 19799 & \\
\hline
\end{tabular}

Table 6: FE regressions with company size, autonomy and industry type dummies. Other control variables as in main $\mathrm{FE}$ regressions but not displayed here.

We have also used the three named variables as matching covariates for the opportunity case (industry, autonomy and company size obviously only apply to the case where individuals start out employed. Including the three variables as additional covariates leads to rather similar results, which we do not report here to conserve space. Apart from these further analyses, we have also conducted the usual robustness checks that the matching technique allows (Caliendo and Kopeinig, 2008). Visual inspection of kernel density plots for the propensity scores show sufficient overlap, and formal calculations of bias reduction show that matching indeed has reduced bias between control and treatment group covariates (typically, less than $10 \%$ bias is deemed acceptable and this was achieved for most of our covariates, see D’Agostino, 1998). ${ }^{12}$

\footnotetext{
${ }^{12}$ We are happy to provide these more detailed diagnostic analyses on request.
} 


\section{Conclusion}

Becoming self-employed is a transformative life event that has an impact on the wellbeing of the self-employed. While it is well-known in the entrepreneurship literature that self-employment positively influences job satisfaction, the effects on overall life satisfaction as well as on satisfaction in different life domains have been less clear. Our study contributed to a better understanding of the welfare effects of self-employment apart from its monetary aspects.

For our German sample, we have found that voluntary ("opportunity") self-employment brings with it positive benefits apart from work satisfaction, and leads to higher overall life satisfaction as well as increased health satisfaction, all of which increase in the first three years of self-employment. Being forced into ("necessity") self-employment to escape unemployment, however, confers no such benefits. Even more so, necessity self-employment leads to increasing dissatisfaction with one's leisure time, an effect that also pertains to a lesser degree to the opportunity self-employed. Our study thus confirms findings for Great Britain (Binder and Coad, 2013a) and in some parts also confirms results for a study of the same German sample (the discrepancies in results here might be due to different measurement methodologies and warrant further research; compare Benz and Frey, 2008a).

Overall, it seems that self-employment only enhances the well-being of the self-employed if it is chosen voluntarily and thus satisfies an individual's need for autonomy (Deci and Ryan, 2000). This is not to say that self-employment cannot be a valid alternative to unemployment and thus be promoted by policy-makers. In these cases, however, where unemployed are prodded and coaxed into (necessity) self-employment, we should not expect that they are happier with this than a comparison group of regular employees.

ca. 6,000 words; Date: April 16, 2014

\section{Appendix}




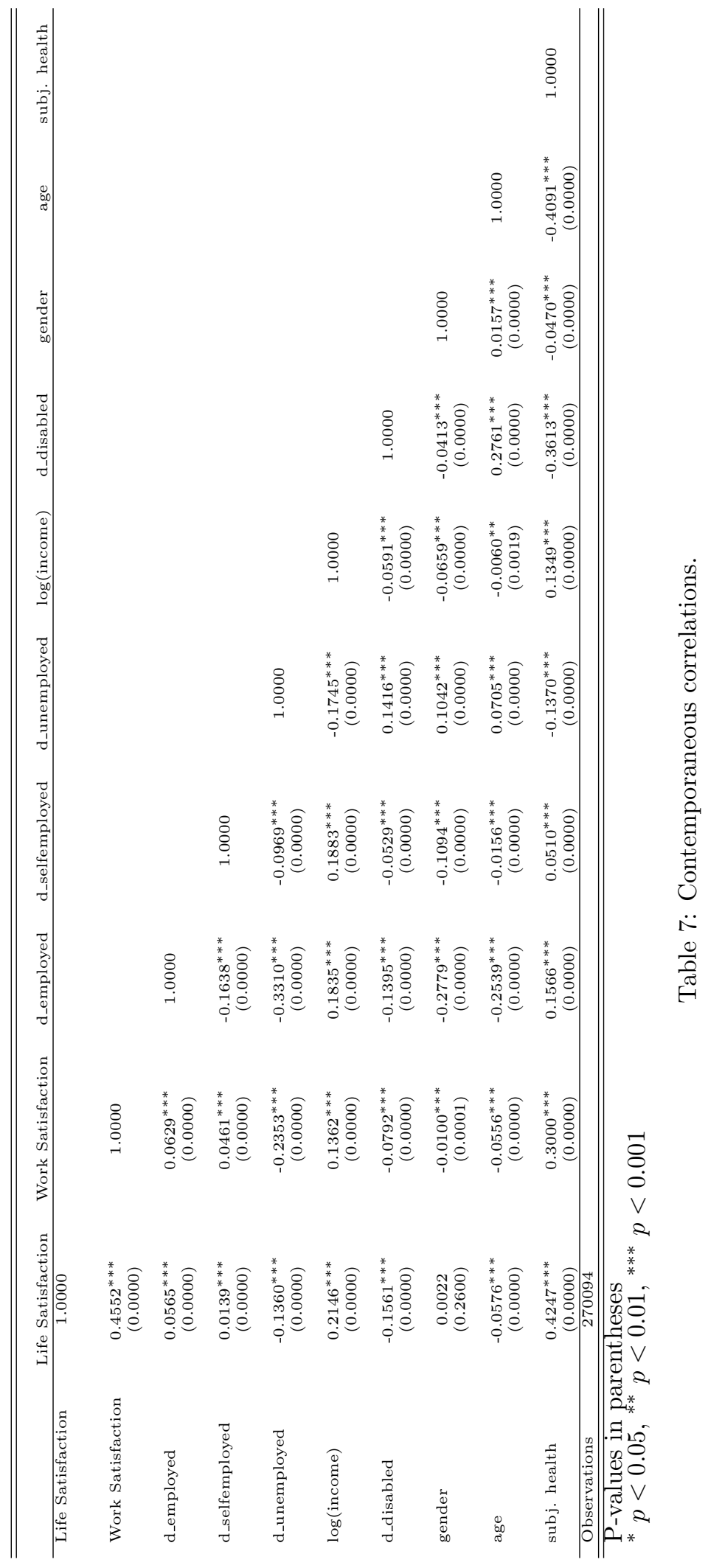




\section{References}

Abadie, A., Drukker, D., Herr, J. L., and Imbens, G. W. (2004). Implementing matching estimators for average treatment effects in stata. The Stata Journal, 4(3):290-311.

Aguinis, H., and Edwards J. R., (2014). Methodological Wishes for the Next Decade and How to Make Wishes Come True. Journal of Management Studies, 51(1):143-174.

Ajayi-obe O. and Parker, S.C. (2005). The Changing Nature of Work among the SelfEmployed in the 1990s: Evidence from Britain. Journal of Labor Research, XXVI(3):501517.

Almus, M. and Czarnitzki, D. (2003). The effects of public R\&D subsidies on firms' innovation activities: The case of Eastern Germany. Journal of Business and Economic Statistics, 21(2):226-236.

Andersson, P. (2008). Happiness and health: Well-being among the self-employed. Journal of Socio-Economics, 37(1):213 - 236.

Benz, M. and Frey, B. S. (2008a). Being independent is a great thing: Subjective evaluations of self-employment and hierarchy. Economica, 75:362-383.

Benz, M. and Frey, B. S. (2008b). The value of doing what you like: Evidence from the selfemployed in 23 countries. Journal of Economic Behavior E3 Organization, 68(3-4):445-455.

Bianchi, M. (2012). Financial development, entrepreneurship, and job satisfaction. Review of Economics and Statistics, 94(1):273-286.

Binder, M. and Coad, A. (2013a). Life satisfaction and self-employment: A matching approach. Small Business Economics, 40(4):1009-1033.

Binder, M. and Coad, A. (2013b). Subjective well-being and unemployment: A quantile treatment approach. Mimeo.

Blanchflower, D. G. (2000). Self-employment in OECD countries. Labour Economics, $7(5): 471-505$.

Blanchflower, D. G. (2004). Self-employment: More may not be better. Swedish Economic Policy Review, 11:15-73.

Blanchflower, D. G., Oswald, A., and Stutzer, A. (2001). Latent entrepreneurship across nations. European Economic Review, 45(4-6):680-691.

Blanchflower, D. G. and Oswald, A. J. (1998). What makes an entrepreneur? Journal of Labor Economics, 16(1):26-60.

Block, J. and Koellinger, P. (2009). I can't get no satisfaction - necessity entrepreneurship and procedural utility. Kyklos, 62(2):191-209.

Böckerman, P. and Ilmakunnas, P. (2009). Unemployment and self-assessed health: Evidence from panel data. Health Economics, 18:161-179. 
Caliendo, M. and Kopeinig, S. (2008). Some practical guidance for the implementation of propensity score matching. Journal of Economic Surveys, 22(1):31-72.

Caliendo, M. and Kritikos, A. (2011). Searching for the entrepreneurial personality: New evidence and avenues for further research. Mimeo.

Carree, M. A. and Verheul, I. (2012). What makes entrepreneurs happy? determinants of satisfaction among founders. Journal of Happiness Studies, 13(2):371-387.

Carter, N. M., Gartner, W. B., Shaver, K. G., and Gatewood, E. J. (2003). The career reasons of nascent entrepreneurs. Journal of Business Venturing, 18(1):13-39.

Carter, S. (2011). The rewards of entrepreneurship: Exploring the incomes, wealth and economic well-being of entrepreneurial households. Entrepreneurship Theory and Practice, $35(1): 39-55$.

Clark, A., Colombier N., and Masclet D. (2008). Never the same after the first time: the satisfaction of the second-generation self-employed. International Journal of Manpower, 29(7):591-609.

Cooper, A. C. and Artz, K. W. (1995). Determinants of satisfaction for entrepreneurs. Journal of Business Venturing, 10:439-457.

Craig, J. B., Schaper, M., and Dibrell, C. (2007). Life in small business in australia: Evidence from the hilda survey. Mimeo.

D'Agostino, R. B. (1998). Propensity score methods for bias reduction in the comparison of a treatment to a non-randomized control group. Statistics in Medicine, 17(19):2265-2281.

D'Ambrosio, C. and Frick, J. R. (2007). Individual well-being in a dynamic perspective. IZA Discussion Paper No. 2618; SOEP Paper No. 5. Available at SSRN: http://ssrn.com/abstract $=969617$.

Deci, E. L. and Ryan, R. M. (2000). The "what" and "why" of goal pursuits: Human needs and the self-determination of behavior. Psychological Inquiry, 11(4):227-268.

Diener, E. and Lucas, R. E. (1999). Personality and subjective well-being. In Kahneman et al. (1999), chapter 11, pages 213-229.

Diener, E., Suh, E., Lucas, R. E., and Smith, H. L. (1999). Subjective well-being: Three decades of progress. Psychological Bulletin, 125(2):276-302.

Dolan, P., Peasgood, T., and White, M. (2008). Do we really know what makes us happy? A review of the economic literature on the factors associated with subjective well-being. Journal of Economic Psychology, 29:94-122.

Evanschitzky, H., Baumgarth, C., Hubbard, R., and Armstrong J.S., (2007). Replication research's disturbing trend. Journal of Business Research 60:411-415. 
Feldman, D. and Bolino, M. (2000). Career patterns of the self-employed: career motivations and career outcomes. Journal of Small Business Management, 38(3):53-68.

Fernandez-Dols, J.-M. and Ruiz-Belda, M.-A. (1995). Are smiles a sign of happiness?: Gold medal winners at the Olympic games. Journal of Personality and Social Psychology, 69(6):1113-1119.

Ferrer-i-Carbonell, A. and Frijters, P. (2004). How important is methodology for the estimates of the determinants of happiness? The Economic Journal, 114:641-659.

Frey, B. S. and Stutzer, A. (2002). What can economists learn from happiness research? Journal of Economic Literature, 40(2):402-435.

Frey, B. S. and Stutzer, A. (2005). Beyond outcomes: Measuring procedural utility. Oxford Economic Papers, 57:90-111.

Fuchs-Schündeln, N. (2009). On preferences for being self-employed. Journal of Economic Behavior $\&$ Organization, 71(2):162-171.

Graham, C. (2009). Happiness around the world. Oxford University Press, Oxford/New York.

Haisken-DeNew, J. and Frick, J. R. (2005). DTC - Desktop Companion to the German Socio-Economic Panel (SOEP). Version 8.0 - Dec 2005, Berlin.

Hamilton, B. H. (2000). Does entrepreneurship pay? an empirical analysis of the returns of self-employment. Journal of Political Economy, 108(3):604-631.

Harbi, S. E. and Grolleau, G. (2012). Does self-employment contribute to national happiness? The Journal of Socio-Economics, 41(5):670-676.

Headey, B., Muffels, R., and Wooden, M. (2004). Money doesn't buy happiness ... or does it? A reconsideration based on the combined effects of wealth, income and consumption. Melbourne Institute Working Paper No.15/04.

Helliwell, J. F. and Wang, S. (2012). The state of world happiness. In Helliwell, J., Layard, R., and Sachs, J., editors, World Happiness Report, chapter 2. The Earth Institute.

Henrekson, M. and Johansson, D. (2010). Gazelles as job creators: a survey and interpretation of the evidence. Small Business Economics, 35:227-244.

Hundley, G. (2001). Why and when are the self-employed more satisfied with their work? Industrial Relations: A Journal of Economy and Society, 40(2):293-316.

Hyytinen, A. and Ruuskanen, O. (2007). Time use of the self-employed. Kyklos, 60(1):105122.

Ichino, A., Mealli, F., and Nannicini, T. (2008). From temporary help jobs to permanent employment: What can we learn from matching estimators and their sensitivity? Journal of Applied Econometrics, 23(3):305-327. 
Idson, T. L. (1990). Establishment size, job satisfaction and the structure of work. Applied Economics, 22(8):1007-1018.

Imbens, G. W. (2004). Nonparametric estimation of average treatment effects under exogeneity: A review. The Review of Economics and Statistics, 86(1):4-29.

Kahneman, D., Diener, E., and Schwarz, N., editors (1999). Well-Being: The Foundations of Hedonic Psychology. Russell Sage Foundation, New York.

Kawaguchi, D. (2008). Self-employment rents: Evidence from job satisfaction scores. Hitotsubashi Journal of Economics, 49(1):35-45.

Krause, A. (2012). Don't worry, be happy? happiness and reemployment. Mimeo.

Krueger, A. B. and Schkade, D. (2008). The reliability of subjective well-being measures. Journal of Public Economics, 92:1833-1845.

Layard, R., Clark, A. E., and Senik, C. (2012). The causes of happiness and misery. In Helliwell, J., Layard, R., and Sachs, J., editors, World Happiness Report, chapter 3, pages 58-90. The Earth Institute.

Layard, R., Mayraz, G., and Nickell, S. (2008). The marginal utility of income. Journal of Public Economics, 92:1846-1857.

Layard, R., Mayraz, G., and Nickell, S. (2010). Does relative income matter? Are the critics right? In Diener, E., Helliwell, J. F., and Kahneman, D., editors, International Differences in Well-Being. Oxford University Press, New York.

Lechner, M. (2009). Long-run labour market and health effects of individual sports activities. Journal of Health Economics, 28(4):839-854.

Leuven, E. and Sianesi, B. (2003). Psmatch2: Stata module to perform full mahalanobis and propensity score matching, common support graphing, and covariate imbalance testing. http://ideas.repec.org/c/boc/bocode/s432001.html.

McAdams, K., Lucas, R., and Donnellan, M. (2012). The role of domain satisfaction in explaining the paradoxical association between life satisfaction and age. Social Indicators Research, 109(2):295-303.

Millán, J., Hessels, J., Thurik, R., and Aguado, R. (2013). Determinants of job satisfaction: a european comparison of self-employed and paid employees. Small Business Economics, 40(3):651-670.

Noorderhaven, N., Thurik, R., Wennekers, S., and Stel, A. v. (2004). The role of dissatisfaction and per capita income in explaining self-employment across 15 european countries. Entrepreneurship Theory and Practice, 28(5):447-466.

Oakes, J. M. and Kaufman, J. S. (2006). Propensity score matching for social epidemiology. In Oakes, J. M. and Kaufman, J. S., editors, Methods in Social Epidemiology, chapter 15, pages 364-386. Jossey-Bass/Wiley, San Francisco. 
Parasuraman, S. and Simmers C. A. (2001). Type of employment, work-family conflict and well-being: a comparative study. Journal of Organizational Behavior, 22:551-568.

Powdthavee, N. (2012). Jobless, friendless and broke: What happens to different areas of life before and after unemployment? Economica, 79(315):557-575.

Praag, M. C. v. and Versloot, P. H. (2007). What is the value of entrepreneurship? a review of recent research. Small Business Economics, 29:351-382.

Reynolds, P., Bosma, N., Autio, E., Hunt, S., De Bono, N., Servais, I., Lopez-Garcia, P., and Chin, N. (2005). Global entrepreneurship monitor: data collection design and implementation 1998-2003. Small Business Economics, 24(3):205-231.

Sandvik, E., Diener, E., and Seidlitz, L. (1993). Subjective well-being: The convergence and stability of self-report and non-self-report measures. Journal of Personality, 61(3):317-342.

Santarelli, E. and Vivarelli, M. (2007). Entrepreneurship and the process of firms' entry, survival and growth. Industrial and Corporate Change, 16(3):455-488.

Sarasvathy, S. D. (2004). The questions we ask and the questions we care about: reformulating some problems in entrepreneurship research. Journal of Business Venturing, 19:707-717.

Schieman, S., Whitestone, Y. K., and Van Gundy, K. (2006). The Nature of Work and the Stress of Higher Status. Journal of Health and Social Behavior, 47:242-257.

Schjoedt, L. and Shaver, K. G. (2007). Deciding on an entrepreneurial career: A test of the pull and push hypotheses using the panel study of entrepreneurial dynamics data. Entrepreneurship Theory and Practice, 31(5):733-752.

Schwarz, N. and Strack, F. (1999). Reports of subjective well-being: Judgmental processes and their methodological implications. In Kahneman et al. (1999), chapter 4, pages 61-84.

Stevenson, B. and Wolfers, J. (2008). Economic growth and subjective well-being: Reassessing the Easterlin paradox. Brookings Papers on Economic Activity, Spring 2008:1-87.

Storey, D. J. (1994). Understanding the Small Business Sector. Routledge, London.

van Praag, B., Frijters, P., and i Carbonell, A. F. (2003). The anatomy of subjective wellbeing. Journal of Economic Behavior \& Organization, 51(1):29-49.

Wagner, G. G., Frick, J. R., and Schupp, J. (2007). The German Socio-Economic Panel Study (SOEP) - Scope, Evolution and Enhancements. Schmollers Jahrbuch, 1:139-169. 


\section{Recent papers in the SPRU Working Paper Series:}

SWPS 2014-06. Andy Stirling. April 2014. "From Sustainability to Transformation: Dynamics and diversity in reflexive governance of vulnerability."

SWPS 2014-07. Ralitsa Petrova Hiteva and Tomas Maltby. April 2014. "Standing in the way by standing in the middle: the case of state-owned natural gas intermediaries in Bulgaria."

SWPS 2014-08. Sabine Hielscher and Adrian Smith. May 2014. "Community-based digital fabrication workshops: A review of the research literature."

SWPS 2014-09. José García-Quevedo, Gabriele Pellegrino and Maria Savona. May 2014. "Reviving demand-pull perspectives: The effect of demand uncertainty and stagnancy on R\&D strategy."

SWPS 2014-10. Daniele Rotolo, Ismael Rafols, Michael Hopkins, and Loet Leydesdorff. June 2014.

"Scientometric Mapping as a Strategic Intelligence Tool for the Governance of Emerging Technologies."

SWPS 2014-11. Andy Stirling and Josie Coburn. June 2014. “Multicriteria Mapping Manual Version 1.0.”

SWPS 2014-12. Anabel Marin, Lilia Stubrin and Patrick van Zwanenberg. June 2014. "Developing capabilities in the seed industry: which direction to follow?."

SWPS 2014-13: Mariana Mazzucato, Carlota Perez. July 2014. "Innovation as Growth Policy: the challenge for Europe."

SWPS 2014-14: Daniele Rotolo, Loet Leydesdorff. July 2014. "Matching MEDLINE/PubMed Data with Web of Science (WoS): A Routine in $R$ language."

SWPS 2014-15: Patrick van Zwanenberg, Erik Millstone. August 2014. "Taste and power: The flavouring industry and flavour additive regulation."

SWPS 2014-16: Steve Sorrell. August 2014. "Energy Substitution, Technical Change and Rebound Effects."

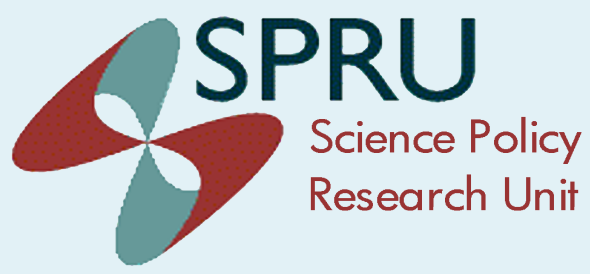

SPRU

Science Policy Research Unit University of Sussex

Falmer, Brighton, BN1 9SL, UK www.sussex.ac.uk/spru 